\title{
Prevalence of Gilbert Syndrome in Bangladesh
}

\author{
Sanjana Zaman 1,2, Hiroko Fukushima1, Ryoko Suzuki', Mohammad Delwer Hossain Hawlader ${ }^{2 *}$, \\ Shoji Yoshimatsu' ${ }^{1,3}$, Yu Kanai ${ }^{4}$, Gias U. Ahsan², Takashi Fukushima ${ }^{1}$
}

${ }^{1}$ Department of Child Health, Faculty of Medicine, University of Tsukuba, Tsukuba, Japan

${ }^{2}$ Department of Public Health, North South University, Dhaka, Bangladesh

${ }^{3}$ Department of Pediatrics, University of Tsukuba Hospital, Tsukuba, Japan

${ }^{4}$ Department of Pediatrics, National Hospital Organization Minami Kyoto Hospital, Kyoto, Japan

Email: ${ }^{*}$ mohammad.hawlader@northsouth.edu

How to cite this paper: Zaman, S., Fukushima, H., Suzuki, R., Hawlader, M.D.H., Yoshimatsu, S., Kanai, Y., Ahsan, G.U. and Fukushima, T. (2018) Prevalence of Gilbert Syndrome in Bangladesh. Open Journal of Blood Diseases, 8, 1-9. https://doi.org/10.4236/ojbd.2018.81001

Received: December 11, 2017

Accepted: March 6, 2018

Published: March 9, 2018

Copyright $\odot 2018$ by authors and Scientific Research Publishing Inc. This work is licensed under the Creative Commons Attribution International License (CC BY 4.0).

http://creativecommons.org/licenses/by/4.0/

\section{(c) (i) Open Access}

\begin{abstract}
Background: Gilbert syndrome (GS) is characterized by an elevated serum bilirubin due to a polymorphism in Uridine Diphosphate Glucuronosyl Transferase (UGT1A1) gene. Several studies have found high prevalence of Gilbert Syndrome in some Asian countries but still haven't explored in Bangladesh. Aim of this study was to determine the allele frequencies of two different variants of UGT1A1 polymorphisms (UGT1A1 6 and UGT1A1 28) among Bangladeshi population. Materials and method: Total 150 unrelated volunteer from outpatient unit of the Central Hospital Limited, and Bangabandhu Sheikh Mujib Medical University, Dhaka were enrolled in this study. Peripheral blood was obtained from each subject and DNA extraction was done by Genomic DNA Isolation Kit. Polymorphisms of UGT1A1*6 (c.211G>A) was genotyped using the TaqMan Assay-on-Demand SNP Typing System and UGT1A1 ${ }^{\star} 28$ (c. $\left.-53 \_-52 \mathrm{TA}\right)$ promoter repeat number polymorphism was determined by PCR method on an ABI PRISM 3130 Genetic Analyzer. Results: $57.3 \%$ of the study participants were male, mean age of them was 4.05 years. Minor allele frequency (MAF) was $0.442(44.2 \%)$ for $U G T 1 A 1^{\star} 28$ and 0.047 (4.7\%) for $U G T 1 A 1^{*} 6$. Conclusion: This is the first ever study conducted among Bangladeshi population to identify the Gilbert syndrome and found very high prevalence. Drugs those who are conjugated by UGT1A1 may lead to worse adverse event due to UGT1A1 polymorphism. Infants having decreased UGT1A1 enzyme activity develop neonatal jaundice and its further complication like Kernicterus. Higher incidence of Gilbert syndrome among Bangladeshi might be the alert for the clinicians treating neonatal jaundice.
\end{abstract}

\section{Keywords}

Gilbert Syndrome, Uridine Diphosphate Glucuronosyl Transferase 
(UGT1A1), Hyperbilirubinemia, Bangladesh

\section{Introduction}

Gilbert syndrome (GS) is defined as a fluctuating or discrete elevation of unconjugated serum bilirubin where hemolysis, liver disease or other causes are excluded. Among the general population, Gilbert syndrome is the main cause of unconjugated hyperbilirubinemia [1]. A. Gilbert [2] described this syndrome as a "imple familial jaundice". Thereafter, Meulengracht described Gilbert syndrome as "icterus intermittens juvenilis" [3], as it is benign and intermittent episodic in character.

In Gilbert syndrome, the mild jaundice occurs as a result of inherited unconjugated hyperbilirubinemia, the most common human metabolic disorders which is caused by polymorphisms in UDP-glucuronosyltransferase 1 (UGT1A1). UGT is a member of super family of enzymes which catalyzes the glucuronidation of many substrates (both exo and endogenous) and UGT1A1 is also the isozyme that is able to conjugate bilirubin, the endogenous yellow pigment which comes from haeme catabolism [4]. Till to date, more than one hundred variants have been found in the UGT1A1 gene, among them $U G T 1 A 1{ }^{*} 28$, $U G T 1 A 1^{\star} 6$ and $U G T 1 A 1^{\star} 27$ are associated with the phenotype of Gilbert syn-

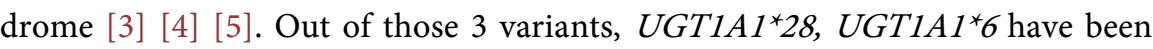
found to be commonly associated in Asian population [6]. The UGT1 gene expresses 9 functional $U G T 1 A$ proteins, and UGT1A1 is the major protein that catalyzes the glucuronidation [7]. Variants of the UGT1A1 gene polymorphism results in the absence or reduction of UGT1A1 activity which may lead to unconjugated hyperbilirubinemia. The $U G T 1 A 1^{*} 28$ polymorphism occurs as insertion of a thymine-adenine (TA) dinucleotide in the TATAA box of the promoter region and it results in genotype of $\mathrm{A}(\mathrm{TA}) 7 \mathrm{TAA}$ and $\mathrm{A}(\mathrm{TA}) 8 \mathrm{TAA}$, the mutant variety which is opposite of the $\mathrm{A}(\mathrm{TA}) 6 \mathrm{TAA}$ the wild variety [8] [9]. $U G T 1 A 1^{*} 28$ polymorphism is classified depending on the number of TA repeats in 2 alleles: 1) TA6/TA6 (wild type), 2) TA6/TA7 (heterozygous mutant), or 3) TA7/TA7 (homozygous mutant).

The TA6/TA7 or TA7/TA7 mutants are associated with decreased enzyme activity and, which may account for increased irinotecan related toxicity [10]. UGT1A1 28 has been reported to cause approximately 70 per cent reduction of UGT1A enzyme activity [10] UGT1A1 28 has severe toxicities with irinotecan which is an anti-cancer drug compared to wild type UGT1A1 1 or heterozygous UGT1A1 28.

There is ethnic variability in $U G T 1 A 1^{\star} 28$ polymorphism. The prevalence of homozygous TA7/TA7 was significantly higher among African (12\% - 27\%) and in Caucasian $(5 \%-15 \%)$ but it is lower $(1.2 \%-5 \%)$ in South-east Asian $(1.2 \%$ 5\%) and Pacific region [11] [12] [13] [14]. The UGT1A1 gene TA7 variant is as- 
sociated with increased bilirubin levels in normal individual [4], or glucose-6-phosphate dehydrogenase (G6PD) deficiency [15], or in $\beta$-thalassemia minor (heterozygous) [16], and it is also associated with neonatal jaundice in G6PD deficiency [17] and hereditary spherocytosis [18]. Genotyping of polymorphisms in UGT1A1 gene is an important step to determine the etiology of free hyperbilirubinemia. Till now, distribution of Gilbert Syndrome (GS) from Bangladesh has not been reported. Therefore, we aimed to determine the genetic profile (prevalence of polymorphisms of UGT1A1) which causes the Gilbert syndrome among Bangladeshi population.

\section{Materials and Methods}

A total of 150 apparently healthy Bangladeshi children presented with minor diseases such as colds, diarrhea, or other minor illnesses were enrolled over a one-year period between January 2013 and December 2013 from the outpatient department of Bangabandhu Sheikh Mujib Medical University (BSMMU) and Central Hospital Limited, Dhaka, Bangladesh. We explained the objectives of the study to the legal guardians. After obtaining written informed consent from all participants, venous blood sample was obtained in Ethylene diamine tetra acetic acid (EDTA) tubes from each subject. After collection, blood sample were shifted to the University of Tsukuba, Japan and then genetic analysis was performed in the genetic lab of the University of Tsukuba. This study was approved by the ethical review committees of BSMMU, Central Hospital Limited, and the University of Tsukuba Hospital.

\section{DNA Extraction and Genotyping}

DNA was extracted using Genomic DNA Isolation Kit (QiAamp DNA Blood Mini Kit, Qiagen, Vealo, Netherlands) from 0.5 to $2 \mathrm{ml}$ peripheral blood following the manufacturer's instructions. Polymorphisms of UGT1A1*6 (c.211G > A) was genotyped using the TaqMan Assay-on-Demand SNP Typing System (Applied Bio Systems, Foster City, CA, USA) following the manufacturer's instructions. PCR was performed on a 384-well format with $5 \mathrm{ng}$ of DNA each, and automatic allele calling was performed using ABI PRISM 7900HT data collection and analysis software, version 2.2.2 (Applied Biosystems). UGT1A1²8 (c.-53_-52TA) promoter repeat number polymorphism was determined by PCR method on an ABI PRISM 3130 Genetic Analyzer (Applied Biosystems). Descriptive statistics were performed by using SPSS statistics version 21.0 (IBM Corporation, NY, USA) and data were expressed as number, percentage, mean and standard deviation.

\section{Results}

Table 1 shows that among the 150 study children, 86 (57.3\%) were male and rest of them were female. Age of the study participants was $4.03 \pm 2.05$ (mean \pm SD) years. Weight and height of the study participants was $15.86 \pm 5.88 \mathrm{~kg}$ (mean \pm 
SD) and $101.80 \pm 16.50 \mathrm{~cm}$ (mean $\pm \mathrm{SD}$ ) respectively. Mid upper arm circumference (MUAC) of the study participants was $15.35 \pm 2.62$ (mean $\pm \mathrm{SD}$ ). Out of 150 blood sample, all samples were successfully genotyped for $U G T 1 A 1^{\star} 6$ and 149 were genotyped for $U G T 1 A 1^{\star} 28$. Table 2 shows that minor allele frequency of UGT1A $1^{\star} 28$ are: wild/wild is $31.33 \%$ (47), wild/mutant is $48 \%$ (72), mutant/mutant $20 \%$ (30) and this table also shows that majority of minor allele frequency of $\mathrm{UGT} \mathrm{A} 1^{\star} 6$ is wild/wild (94.66\%), few of them is wild/mutant (4.66\%) and only 1 is mutant/mutant. Overall minor allele frequency (MAF) were $0.442(44.2 \%)$ for $U G T 1 A 1^{\star} 28$ and $0.047(4.7 \%)$ for $U G T 1 A 1^{\star} 6$. Table 3 shows the comparison of allele frequencies of $U G T 1 A 1^{\star} 28 \& U G T 1 A 1^{\star} 6$ in different ethnicity and found $U G T 1 A 1^{*} 28$ is very high among Bangladeshi population in compare to other ethnicity but low in $\mathrm{UGT}^{\mathrm{A}} 1^{\star} 6$ in compare to other Asian population.

Table 1. Characteristics of the study participants.

\begin{tabular}{cc}
\hline Characteristics & mean \pm SD \\
\hline Age (year) & $4.03 \pm 2.05$ \\
Weight $(\mathrm{kg})$ & $15.86 \pm 5.88$ \\
Height $(\mathrm{cm})$ & $101.80 \pm 16.50$ \\
Sex & $\mathrm{n}(\%)$ \\
Male & $86(57.33 \%)$ \\
Female & $64(42.66 \%)$ \\
\hline
\end{tabular}

Table 2. Frequency of minor allele.

\begin{tabular}{cc}
\hline \multicolumn{1}{c}{ UGT1A1*28 (genotyped 149) $\mathrm{n}(\%)$} \\
\hline Wild/wild & $47(31.33)$ \\
Wild/mutant & $72(48.00)$ \\
Mutant/mutant & $30(20.00)$ \\
Not genotyped & $1(00.66)$ \\
\hline & UGT1A1*6 (genotyped = 150) \\
\hline Wild/wild & $142(94.66)$ \\
Wild/mutant & $7(4.66)$ \\
Mutant/mutant & $1(0.66)$ \\
\hline
\end{tabular}

Table 3. Comparison of Allele frequencies of $U G T 1 A 1^{\star} 28$ \& $U G T 1 A 1^{\star} 6$ in other ethnicity.

\begin{tabular}{ccc}
\hline Ethnicity & UGT1A1 $^{* 28}$ & UGT1A1 $^{* 6} \mathbf{6}$ \\
\hline Caucasian & 0.312 & 0.029 \\
Japanese & 0.104 & 0.196 \\
Chinese & 0.186 & 0.186 \\
Indian & 0.280 & 0.160 \\
Bangladeshi & 0.442 & 0.047 \\
\hline
\end{tabular}

UGT1AI ${ }^{*} 28$ \& ${ }^{*} 6$ in other ethnicity; ${ }^{*}$ Li Minmin et al. 2014, Agrawal SK et al. 2009; MAF data of Caucasian was collected from NCBI dbSNP database. 


\section{Discussion}

This is the first ever study where we evaluated the frequency of the main genetic determinant of Gilbert Syndrome (UGT1A1 ${ }^{*} 28$ and $U G T 1 A 1^{*} 6$ ) among Bangladeshi population. Our result confirms that $U G T 1 A 1^{*} 28$ polymorphism is a highly frequent condition among Bangladeshi population. Previously it was believed that, this is not a disease of Bangladeshi population, that's why there was no interest to conduct research on Gilbert syndrome among Bangladeshi population. We believe this finding will completely change the perception level of clinician as well as researcher in Bangladesh. Now a day it is evident that there is an inter-individual and interethnic variation in glucuronidation [19]. There is a wide range of diversification among UGT family. This is best explained by the UGT1A1 gene, which is responsible for over 50 genetic lesions [20]. It has been reported that, among Caucasian the frequency of the $U G T 1 A 1^{\star} 28$ variant allele is $30 \%-45 \%$. Among African and Indian populations, the distribution is twice that of the $10 \%-20 \%$ reported in East Asian populations [21] [22] [23] [24] [25]. In Uzbekistan, the incidence of UGT1A1*28 homozygotes was $9.3 \%$, which was higher than that in the Japanese population was studied previously [26]. Other published reports shown that, UGT1A1*28 homozygotes is high in distribution in Europe (5\% - 14.8\%), Africa (5.9\% $17.9 \%)$, and India $(12.8 \%-19.3 \%)$; and less frequent in Japan and East Asia and $(0 \%-5.9 \%)$ [27]-[36].

Individuals with Gilbert syndrome have reduced UGT activity due to UGT1A lgene polymorphism. This reduced UGT activity causes jaundice under the conditions such as illness, physical exertion or fasting. Study among Malaysian population concluded that Gilbert syndrome is associated with a homozygous (TA7) in Malaysian population. They found the levels of serum bilirubin in GS patients from $20 \mu \mathrm{M}$ to $90 \mu \mathrm{M}$ [37]. Due to decreased UGT1A1 enzyme activity, neonates with this syndrome have higher risk to develop neonatal jaundice results in further complications like Kernicterus and irreversible brain damage. In a recent study, higher polymorphism of the UGT1A lgene was found to be significantly associated with hyperbilirubinemia among North Indian neonates [38]. Another study concludes that, UGT1Alpolymorphism is a risk factor for severe neonatal unconjugated hyperbilirubinemia among Malaysian population [39]. Moreover, UGT1A1 ${ }^{*} 28$ allele is associated with reduced levels of enzyme. Therefore modification of dosage of irinotecan should be done on the basis of patients' UGT1A1 genotyping. Thereby, adverse effects of this drug can be avoided to some extent. The FDA in USA approved an amendment of the label for Camptosar (irinotecan hydrochloride) which is invariably used as chemotherapeutic agent for the treatment of colon cancer, which includes the warning to reduce the starting dose of irinotecan for $U G T 1 A 1^{*} 28$ homozygous patients. For East Asian individuals, requires both $U G T 1 A 1^{*} 6$ and $U G T 1 A 1^{*} 28$ genotyping, since there is no linkage disequilibrium between the two polymorphisms [40]. 


\section{Conclusion}

Our study found the evidence of very high prevalence of UGT1A1 polymorphism among Bangladeshi population. This newly discovered result might be the alert for the clinicians treating neonatal jaundice at children hospital in Bangladesh. It is well known that most of the children with Kernicterus have no underlying etiological identity to explain the hyperbilirubinemia. In fact, preventing a case of Kernicterus might be one of the most valuable strategies in all healthcare settings, resulting in a healthy baby rather than a child with a life-time of debilitating neurodevelopment handicaps. UGT1A1 polymorphism also has an implication in case of treatment of cancer. We recommend genotyping of UGT1A1 prior to management of neonatal jaundice as well as before treating by irinotecan chemotherapy as patients with UGT1A1 polymorphism having more adverse effects of this chemotherapeutic agent. Furthermore, study regarding the correlation between prevalence of polymorphism and hyperbilirubinemia is an urgent need.

\section{Acknowledgements}

We would like to express our thanks and gratitude to the University of Tsukuba, Bangabandhu Sheikh Mujib Medical University (BSMMU) and Central Hospital for their support. We would also like to thanks to the study participants for their voluntary contribution to this study. This work was supported by a grant from the Grant of National Center for Child Health and Development (25-2), Japan. We dedicate this article to the National Professor of Pediatrics, Bangladesh Dr. MR Khan.

\section{References}

[1] Fevery, J. (2008) Bilirubin in Clinical Practice: A Review. Liver International, 28, 592-605. https://doi.org/10.1111/j.1478-3231.2008.01716.x

[2] Gilbert, A.L.P. (1901) The Cholemie Simple Familiale. Semaine Medicale, 21, 241-243

[3] Meulengracht, E. (1947) A Review of Chronic Intermittent Juvenile Jaundice. QJM, 16, 83-98.

[4] Bosma, P.J., Chowdhury, J.R., Bakker, C., Gantla, S., de Boer, A., Oostra, B.A., et al. (1995) The Genetic Basis of the Reduced Expression of Bilirubin UDP-Glucuronosyltransferase 1 in Gilbert's Syndrome. New England Journal of Medicine, 333, 1171-1175. https://doi.org/10.1056/NEJM199511023331802

[5] Strassburg, C.P. and Manns, M.P. (2000) Jaundice, Genes and Promoters. Journal of Hepatology, 33, 476-479. https://doi.org/10.1016/S0168-8278(00)80285-8

[6] Li, M., Wang, Z., Guo, J., et al. (2014) Clinical Significance of UGT1A1 Gene Polymorphisms on Irinotecan-Based Regimens as the Treatment in Metastatic Colorectal Cancer. Onco Targets and Therapy, 23, 1653-1661.

[7] Mackenzie, P.I., Owens, I.S., Burchell, B., et al. (1997) The UDP Glycosyltransferase Gene Superfamily: Recommended Nomenclature Update Based on Evolutionary Divergence. Pharmacogenetics, 7, 255-269.

https://doi.org/10.1097/00008571-199708000-00001 
[8] Monaghan, G., Ryan, M., Seddon, R., Hume, R. and Burchell, B. (1996) Genetic Variation in Bilirubin UDP-Glucuronosyltransferase Gene Promoter and Gilbert's Syndrome. Lancet, 347, 578-581. https://doi.org/10.1016/S0140-6736(96)91273-8

[9] Raijmakers, M.T., Jansen, P.L., Steegers, E.A. and Peters, W.H. (2000) Association of Human Liver Bilirubin UDP-Glucuronyltransferase Activity with a Polymorphism in the Promoter Region of the UGT1A1 Gene. Journal of Hepatology, 33, 348-351. https://doi.org/10.1016/S0168-8278(00)80268-8

[10] Innocenti, F., Vokes, E.E. and Ratain, M.J. (2006) Irinogenetics: What Is the Right Star? Journal of Clinical Oncology, 24, 2221-2224. https://doi.org/10.1200/JCO.2005.05.2464

[11] Yong, W.P., Innocenti, F. and Ratain, M.J. (2006) The Role of Pharmacogenetics in Cancer Therapeutics. British Journal of Clinical Pharmacology, 62, 35-46. https://doi.org/10.1111/j.1365-2125.2006.02591.x

[12] Hall, D., Ybazeta, G., Destro-Bisol, G., Petzl-Erler, M.L. and Di Rienzo, A. (1999) Variability at the Uridine Diphosphate Glucuronosyltransferase 1A1 Promoter in Human Populations and Primates. Pharmacogenetics, 9, 591-599.

https://doi.org/10.1097/00008571-199910000-00006

[13] Premawardhena, A., Fisher, C.A., Liu, Y.T., et al. (2003) The Global Distribution of Length Polymorphisms of the Promoters of the Glucuronosyltransferase 1 Gene (UGT1A1): Hematologic and Evolutionary Implications. Blood Cells, Molecules, and Diseases, 31, 98-101. https://doi.org/10.1016/S1079-9796(03)00071-8

[14] Huang, C.S., Luo, G.A., Huang, M.L., Yu, S.C. and Yang, S.S. (2000) Variations of the Bilirubin Uridine-Diphosphoglucuronosyl Transferase 1A1 Genein Healthy Taiwanese. Pharmacogenetics, 10, 539-544. https://doi.org/10.1097/00008571-200008000-00007

[15] Galanello, R., Perseu, L., Melis, M.A., Cipollina, L., Barella, S., Giagu, N., Turco, M.P., Maccioni, O. and Cao, A. (1997) Hyperbilirubinaemia in Heterozygous Beta-Thalassaemia Is Related to Co-Inherited Gilbert's Syndrome. British Journal of Haematology, 99, 433-436. https://doi.org/10.1046/j.1365-2141.1997.3703182.x

[16] Sampietro, M., Lupica, L., Perrero, L., Comino, A., Martinez di Montemuros, F., Cappellini, M.D. and Fiorelli, G. (1997) The Expression of Uridine Diphosphate Glucuronosyltransferase Gene Is a Major Determinant of Bilirubin Level in Heterozygous Beta-Thalassaemia and in Glucose-6-Phosphate Dehydrogenase Deficiency. British Journal of Haematology, 99, 437-439. https://doi.org/10.1046/j.1365-2141.1997.4113228.x

[17] Kaplan, M., Renbaum, P., Levy-Lahad, E., Hammerman, C., Lahad, A. and Beutler, E. (1997) Gilbert Syndrome and Glucose-6-Phosphate Dehydrogenase Deficiency: A Dose-Dependent Genetic Interaction Crucial to Neonatal Hyperbilirubinemia. Proceedings of the National Academy of Sciences, 94, 12128-12132. https://doi.org/10.1073/pnas.94.22.12128

[18] Iolascon, A., Faienza, M.F., Moretti, A., Perrotta, S. and Miraglia del Giudice, E. (1998) UGT1 Promoter Polymorphism Accounts for Increased Neonatal Appearance of Hereditary Spherocytosis. Blood, 91, 1093-1094.

[19] Burchell, B., Soars, M., Monaghan, G., Cassidy, A., Smith, D. and Ethell, B. (2000) Drug Mediated Toxicity Caused by Genetic Deficiency of UDP-Glucuronosyltransferases. Toxicology Letters, 112-113, 333-340. https://doi.org/10.1016/S0378-4274(99)00209-X

[20] Kadakol, A., Ghosh, S.S., Sappal, B.S., Sharma, G., Chowdhury, J.R. and Chowdhury, N.R. (2000) Genetic Lesions of Bilirubin Uridinediphosphoglucuronate Glu- 
curonosyl-Transferase (UGT1A1) Causing Crigler-Najjar and Gilbert Syndromes: Correlation of Genotype to Phenotype. Human Mutation, 16, 297-306. https://doi.org/10.1002/1098-1004(200010)16:4<297::AID-HUMU2>3.0.CO;2-Z

[21] Hoskins, J.M., Marcuello, E., Altes, A., Marsh, S., Maxwell, T., Van Booven, D.J., Paré, L., Culverhouse, R., McLeod, H.L. and Baiqet, M. (2008) Irinotecan Pharmacogenetics: Influence of Pharmacodynamic Genes. Clinical Cancer Research, 14, 1788-1796. https://doi.org/10.1158/1078-0432.CCR-07-1472

[22] Chowbay, B., Zhou, S. and Lee, E.J. (2005) An Interethnic Comparison of Polymorphisms of the Genes Encoding Drug-Metabolizing Enzymes and Drug Transporters: Experience in Singapore. Drug Metabolism Reviews, 37, 327-378. https://doi.org/10.1081/DMR-28805

[23] Mercke Odeberg, J., Andrade, J., Holmberg, K., Hoglund, P., Malmqvist, U. and Odeberg, J. (2006) UGT1A Polymorphisms in a Swedish Cohort and a Human Diversity Panel, and the Relation to Bilirubin Plasma Levels in Males and Females. European Journal of Clinical Pharmacology, 62, 829-837. https://doi.org/10.1007/s00228-006-0166-3

[24] Liu, J.Y., Qu, K., Sferruzza, A.D. and Bender, R.A. (2007) Distribution of the UGT1A1*28 Polymorphism in Caucasian and Asian Populations in the US: A Genomic Analysis of 138 Healthy Individuals. Anticancer Drugs, 18, 693-696. https://doi.org/10.1097/CAD.0b013e32803a46fe

[25] Innocenti, F., Grimsley, C., Das, S., Ramirez, J., Cheng, C., Kuttab-Boulos, H., Ratain, M.J. and Di Rienzo, A. (2002) Haplotype Structure of the UDP Glucuronosyltransferase 1A1 Promoter in Different Ethnic Groups. Pharmacogenetics, 12, 725-733. https://doi.org/10.1097/00008571-200212000-00006

[26] Kobayashi, M., Hazama, S., Takahashi, K., Oba, K., Okayama, N., Nishioka, M., Hinoda, Y., Oka, M., Okamoto, K., Maeda, H., Nakamura, D., Sakamoto, J. and Mishima, H. (2012) Is There Diversity among UGT1A1 Polymorphism in Japan? World Journal of Gastrointestinal Oncology, 4, 170-175. https://doi.org/10.4251/wjgo.v4.i7.170

[27] Ando, Y., Saka, H., Ando, M., Sawa, T., Muro, K., Ueoka, H., Yokoyama, A., Saitoh, S., Shimokata, K. and Hasegawa, Y. (2000) Polymorphisms of UDP Glucuronosyltransferase Gene and Irinotecan Toxicity: A Pharmacogenetic Analysis. Cancer Research, 60, 6921-6926.

[28] Okuyama, Y., Hazama, S., Nozawa, H., Kobayashi, M., Takahashi, K., Fujikawa, K., Kato, T., Nagata, N., Kimura, H., Oba, K., Sakamoto, J. and Mishima, H. (2011) Prospective Phase II Study of FOLFIRI for mCRC in Japan, Including the Analysis of UGT1A1 28/6 Polymorphisms. Japanese Journal of Clinical Oncology, 41, 477-482. https://doi.org/10.1093/jjco/hyr001

[29] Toffoli, G., Cecchin, E., Corona, G., Russo, A., Buonadonna, A., D’Andrea, M., Pasetto, L.M., Pessa, S., Errante, D., De Pangher, V., Giusto, M., Medici, M., Gaion, F., Sandri, P., Galligioni, E., Bonura, S., Boccalon, M., Biason, P. and Frustaci, S. (2006) The Role of UGT1A1 ${ }^{\star} 28$ Polymorphism in the Pharmacodynamics and Pharmacokinetics of Irinotecan in Patients with Metastatic Colorectal Cancer. Journal of Clinical Oncology, 24, 3061-3068. https://doi.org/10.1200/JCO.2005.05.5400

[30] Cecchin, E., Innocenti, F., D’Andrea, M., Corona, G., De Mattia, E., Biason, P., Buonadonna, A. and Toffoli, G. (2009) Predictive Role of the UGT1A1, UGT1A7, and UGT1A9 Genetic Variants and Their Haplotypes on the Outcome of Metastatic Colorectal Cancer Patients Treated with Fluorouracil, Leucovorin, and Irinotecan. Journal of Clinical Oncology, 27, 2457-2465. https://doi.org/10.1200/JCO.2008.19.0314 
[31] Kaniwa, N., Kurose, K., Jinno, H., Tanaka-Kagawa, T., Saito, Y., Saeki, M., Sawada, J., Tohkin, M. and Hasegawa, R. (2005) Racial Variability in Haplotype Frequencies of UGT1A1 and Glucuronidation Activity of a Novel Single Nucleotide Polymorphism 686C > T (P229L) Found in an African-American. Drug Metabolism \& Disposition, 33, 458-465. https://doi.org/10.1124/dmd.104.001800

[32] Saeki, M., Saito, Y., Jinno, H., Sai, K., Ozawa, S., Kurose, K., Kaniwa, N., Komamura, K., Kotake, T., Morishita, H., Kamakura, S., Kitakaze, M., Tomoike, H., Shirao, K., Tamura, T., Yamamoto, N., Kunitoh, H., Hamaguchi, T., Yoshida, T., Kubota, K., Ohtsu, A., Muto, M., Minami, H., Saijo, N., Kamatani, N. and Sawada, J.I. (2006) Haplotype Structures of the UGT1A Gene Complex in a Japanese Population. The Pharmacogenomics Journal, 6, 63-75. https://doi.org/10.1038/sj.tpj.6500335

[33] Zhang, A., Xing, Q., Qin, S., Du, J., Wang, L., Yu, L., Li, X., Xu, L., Xu, M., Feng, G. and He, L. (2007) Intra-Ethnic Differences in Genetic Variants of the UGT-Glucuronosyltransferase 1A1 Gene in Chinese Populations. The Pharmacogenomics Journal, 7, 333-338. https://doi.org/10.1038/sj.tpj.6500424

[34] Lamas, M.J., Duran, G., Balboa, E., Bernardes, B., Candamio, S., Vidal, Y., Mosquera, A., Giraldez, J.M., Lopez, R., Carracedo, A. and Barros, F. (2012) The Value of Genetic Polymorphisms to Predict Toxicity in Metastatic Colorectal Patients with Irinotecan-Based Regimens. Cancer Chemotherapy and Pharmacology, 69, 1591-1599. https://doi.org/10.1007/s00280-012-1866-2

[35] Han, J.Y., Lim, H.S., Shin, E.S., Yoo, Y.K., Park, Y.H., Lee, J.E., Jang, I.J., Lee, D.H. and Lee, J.S. (2006) Comprehensive Analysis of UGT1A Polymorphisms Predictive for Pharmacokinetics and Treatment Outcome in Patients with Non-Small-Cell Lung Cancer Treated with Irinotecan and Cisplatin. Journal of Clinical Oncology, 24, 2237-2244. https://doi.org/10.1200/JCO.2005.03.0239

[36] D’Silva, S., Colah, R.B., Ghosh, K. and Mukherjee, M.B. (2013) UDP-Glucuronosyltransferase 1A1 (UGT1A1) Gene Haplotypes and Their Effect on Serum Bilirubin Concentration in Healthy Indian Adults. Gene, 513, 36-39. https://doi.org/10.1016/j.gene.2012.10.081

[37] The, L.K., Hashim, H., Zakaria, Z.A. and Salleh, M.Z. (2012) Polymorphisms of UGT1A1 ${ }^{\star} 6, \mathrm{UGT}_{1 \mathrm{~A}}{ }^{\star} 27 \& \mathrm{UGT} 1 \mathrm{~A} 1{ }^{\star} 28$ in Three Major Ethnic Groups from Malaysia. Indian Journal of Medical Research, 136, 249-259.

[38] Agarwal, S.K., Praveen, K., Ritu, R., Neeraj, S., Reena, D. and Rajendra, P. (2009) UGT1A1 Gene Polymorphisms in North Indian Neonates Presenting with Unconjugated Hyperbilirubinemia. Pediatric Research, 65, 675-680.

[39] Azlin, I., Wong, F.L., Ezham, M., Hafizah, A. and Ainoon, O. (2011) Prevalence of Uridine Glucuronosyl Transferase 1A1 (UGT1A1) Mutations in Malay Neonates with Severe Jaundice. The Malaysian Journal of Pathology, 33, 95-100.

[40] Saito, Y., Maekawa, K., Ozawa, S. and Sawada, J. (2007) Genetic Polymorphisms and Haplotypes of Major Drug Metabolizing Enzymes in East Asians and Their Comparison with Other Ethnic Populations. Current Pharmacogenomics, 5, 49-78. https://doi.org/10.2174/157016007780077202 